\title{
Internal Logic and Implementation Ways of Industry-Education Integration
}

\author{
Hongbing Liao* \\ School of Social Development and Management, Hunan Women's University, Changsha City, Hunan \\ Province \\ *corresponding author.
}

\begin{abstract}
With the popularization of higher education and the optimization of industrial structure, there is an increasing demand for applied talents during the development of the society. The integration of industry and education, as an effective way to cultivate applied talents through college-enterprise cooperation, organically integrates higher education with industries and promotes the comprehensive combination of both structural elements on the supply side of talents and the demand side of industries, which is a new mode for running colleges and universities. The industry-education integration and the college-enterprise cooperation, however, still have problems currently, including insufficient consensus on the concepts, unsound system, inadequate motivation, scant resources and poor system supply. This paper holds that to deepen the industry-education integration, both educational organizations and industries should intercommunicate and integrate with each other, which require the enhancement of the consensus on college-enterprise cooperation, the co-construction of systems, resource sharing, cultural symbiosis, talent integration, win-win benefits and the like, in order to achieve the healthy development of the college-enterprise cooperation.
\end{abstract}

Keywords: Industry-education integration, industrial structure, college-enterprise cooperation; internal logic, implementation approaches.

\section{Background}

China's economy and society have entered a new normality with economic growth mode experiencing changes, leading to profound changes in relationship between talent supply and industrial demand. The talent training structure is incompatible with economic restructuring and industrial transformation and upgrading. More prominent structural contradictions are shown in higher education. Social development urgently needs applied innovative talents, and industry-education integration is an effective way for cultivation of applied talents through school-enterprise cooperation [1]. At the end of 2017, the State Council of China issued the "Several Opinions on Deepening Industry-Education Integration", which clearly stated that industry-education integration should be extended from vocational education to the entire education system. [2] "Establishing a technological innovation system with enterprises as the main body based on market orientation and in-depth integration of industry, education and research"-provides a fundamental path for deepening industry-education integration in the new era [3] "Deepening industry-education integration is a strategic measure to promote the priority development of education, talent-led development, industrial innovation and development, and high-quality economic development, which is characterized by interconnection, synergy and mutual promotion" [4]. The government has established the basic concept and work requirements of industry-education integration from the top-level design level. Our education and industry circles have reached consensus in the concepts of industry-education integration and school-enterprise cooperation.

\section{The Internal Logic of Industry-Education Integration}

\subsection{Connotation of industry-education integration}

In the implementation process of applied talent training, to let industry-education integration move from "consensus" to "co-governance", it is necessary to clarify its logical starting point, thus enabling in-depth development of ISSN: 0010-8189 
industry-education integration.

Different types of education have different industry-education integration bodies. At present, there are two types of industry-education integration bodies, namely, integration of vocational education and industry, and integration of higher education and industry [5]. The cultivation of applied talents through industry-education integration and school-enterprise cooperation has a history of more than 100 years in European and American countries. In "The Vocational School Fallacy in Development Planning", professor Foster (Philip. Foster, 1965) from University of Chicago was the earliest one to put forward the concept of "industry-education integration". In the research, it was found that foreign theoretical circles replaced "cooperative education" with "industry-education integration", emphasizing the cooperative negotiation mechanism between the education system and the industrial system and viewing higher education institutions and industry sectors as both important participants in school running.

There is no unified definition regarding concept of industry-education integration. To explore its connotation, we need understand it from two aspects. One is the definition of the concept of "industry and education". Industry refers to industries, including business and industries. Enterprises as places for "industry" undertake the mission of creating material wealth for economic and social development; education is education, mainly referring to school education. Colleges and universities as the carrier of "education" undertake the mission of cultivating qualified personnel for economic and social development. Industry and education can also refer to "production and education." The other is the definition of the concept of "integration". According to the interpretation of "Ci Hai", integration refers to the fusion of several different things, and the result is a new integration body. Therefore, "industry-education integration" is usually interpreted as the integration of the industrial system and the education system to form a whole.

At present, Chinese scholars hold two views on the connotation analysis of industry-education integration. One is the concept of in-depth cooperation. Scholars holding this view believe that industry-education integration is a deep cooperative partnership. The industrial system and the education system are relatively independent as a social subsystem. Industry-education integration is in-depth cooperation based on respective development needs of higher education institutions and the industry[6]. Industry-education integration is an in-depth cooperation achieved by optimizing the allocation of resources, in which, school education and industry each contribute respective advantageous resources, cooperate with each other, and complement each other [7]. The other is the new idea towards integration. Industry-education integration means the integration of school education and industry to become a new "organizational form." It is believed that industry-education integration emphasizes integration, which refers to the integration of two different things, school education and industry, to form a new body [8]. The education system and the industrial system finally form a brand-new organization, so that school education activities and the production activities of industry enterprises can be organized and carried out at the same time [9].

In summary, industry-education integration means an economic and educational activity mode in which education and industry interact and communicate with each other in in-depth cooperation based on relevant agreements, taking student employment and economic and social development needs as the starting point, resource integration as the basic goal, talent training as the core, school-enterprise cooperation as the platform, mutual benefit as the driving force, project cooperation as the carrier.

\subsection{The Characteristics of Industry-Education Integration}

Industry-education integration is a substantial, in-depth and close integration of school and enterprise, which represents a new model for production-education integration and school-enterprise interaction. The basic characteristics of industry-education integration are as follows:

The first is systematicness. Industry-education integration refers to the organic unity of the two systems, namely education system and industrial system, which is the unity of the elements of the two main bodies, universities and industries, through mutual link and and interaction. The overall implementation of industry-education integration requires elements such as government leadership, university guidance, and enterprise participation, etc.

ISSN: 0010-8189

(C) CONVERTER 2020

www.converter-magazine.info 
The second is diversity. In industry-education integration, both universities and industries are important subjects for the implementation of in-depth industry-education integration. Based on talent training and industrial benefits, they cooperate with each other, communicate with each other and interact with each other. Such cooperation is deep, purposeful and directional. Industry-education integration is a result of multi-participation. The government plays a leading and coordinating role in optimizing and integrating all resources; the industry plays an advocacy role and proposes relevant countermeasures and suggestions for industry development trends and needs; universities and enterprises are the coordinating carriers for industry-education integration, both participating in talent training, school-enterprise cooperation and mutual benefit. Such diversity in participation requires the government to make overall planning and build an industry-education integration platform characterized by complementary advantages, resource sharing, win-win cooperation, collaborative innovation, and common development.

The third is dynamics. Industry-education integration is a dynamic process. In terms of talent training, college education must closely follow the needs of industrial economic development, and the two must dynamically evolve over time to strengthen cooperation and interaction. On the one hand, college education must adapt to the needs of industrial economic development and continuously promote the transformation and upgrading of the industrial structure. On the other hand, enterprise industry must continually put forward new requirements for talent training specifications and industry standards, thereby promoting the reform of college education talent training mode and determining the talent training direction. Therefore, the dynamic evolution of the educational structure and the industrial structure is a normal process, and there is a spiral cycle from adaptation to inadaptability and then to adaptation.

The fourth is linkage. Industry-education integration is the organic unity with "industry" and "education" as the main body, which is a unity of teaching and production, education and industry, universities and enterprises. College education and industry are in a relationship of mutual influence, interaction, and joint development. Industrial transformation and upgrading, technological innovation, and business layout updates will all put forward new requirements for the training of college education talents. Moreover, higher education is also implementing knowledge and technology innovation, which will affect the development of the industrial economy in return and affect the process and efficiency of industry transformation. Therefore, industry enterprises at the demand side of talents and higher education at the supply side of talents must form a joint development relationship, so that development of industries promotes the reform of higher education, while higher education teaching gives full play to the advantages of technology research and development, solves the technical problems of industry enterprises, guides and promotes production development. In this way, the two complement each other, promote each other, and develop in conjunction.

\section{Realistic Problems in Industry-Education Integration}

Industry-education integration is an effective way for colleges and universities to cultivate applied talents, which is also a basic way for local undergraduate colleges to turn to application-oriented universities. We should vigorously promote the industry-education integration, collaborative innovation, and organically link the education chain, the talent chain with the industrial chain and the innovation chain [10], which is the proper meaning of training applied talents for economic and social development in application-oriented colleges. However, there are still some practical problems in the process of industry-education integration and school-enterprise cooperation in higher education.

\subsection{There is no consensus on the concept of industry-education integration.}

Today, higher education has exhibited a popular and universal development trend. Local undergraduate colleges and universities began to shift from traditional academic type to innovative application type. The crisis of the country and society's demand for applied talents forces higher education reform. However, the ideological concepts of some undergraduate colleges and universities fail to conform to the requirements of economic and social development and the requirements of national education reform. The concept of "four returns" regarding higher education put forward

ISSN: 0010-8189 
by General Secretary Xi has not yet formed an organic whole in links such as school management, personnel training, and system construction, etc. Universities and enterprises have not reached a consensus on the implementation path and mechanism for collaborative education in industry-education integration, and the top-level design and talent training model of industry-education integration still lack in-depth communication and implementation in universities and enterprises. All of these affect the enthusiasm for collaborative education through industry-education integration.

3.2 The management system for industry-education integration is not sound

During the planned economy period, China's institutions of higher learning had a natural blood relationship with enterprises. It was more common for industries and enterprises to run schools by themselves, mainly to cultivate applied talents for themselves. The school personnel were mainly appointed by industries or enterprises, and the funds were allocated by industries or enterprises. Most teachers came from industries and enterprises, and students were employed in industries or enterprises. Therefore, industry-education integration was very close. In the late 1990s, the industry-enterprise school-running system was broken. Most ministries and higher education institutions were delegated to local governments under the jurisdiction of the education department. Industries or enterprises no longer run higher education, leading to separation of industry and education. The natural connection between schools and enterprises was split due to the management system changes, leading to reduced industry-education interaction. At present, the country has also introduced some document systems, but the actual effect is not good.

\subsection{Enterprises lack motivation to participate in industry-education integration}

Industry-education integration is a combination of employment and education. Involving capital investment and benefit distribution, it is also a benefit-driven behavior. When colleges and universities promote industry-education integration and school-enterprise cooperation, they consider more about the benefits of college admissions, and pay insufficient attention to the needs of enterprises. Therefore, in the process of school-enterprise cooperation, enterprises pay more and get less benefits, which leads to enterprises' insufficient motivation for industry-education integration. In addition, some enterprises are more utilitarian. Some enterprises regard college students interning in companies as cheap labor, value economic benefits over social responsibility, and most of them lack enthusiasm for industry-education integration. Mostly in a passive state, they lack basic motivation to participate in talent cultivation in colleges and universities, which results in a situation of "hot schools, cold enterprises", and most industry-education integrations rely solely on personal feelings to maintain a cooperative relationship. In this way, progress of industry-education integration and school-enterprise cooperation is difficult, let alone sublimation of cooperation and integration.

\subsection{Colleges and universities pay insufficient attention to industry-education integration}

Industry-education integration is a systematic project of school-enterprise cooperation, involving multiple interests of the cooperative subjects, namely schools and enterprises. In view of its application characteristics, application-oriented undergraduate colleges should act as the active party in cooperation and integration, and pay more attention to industry-education integration and school-enterprise cooperation. However, in the school's internal management, different departments have insufficient understanding towards industry-education integration, resulting in insufficient motivation. For example, there will be many uncertain factors if students and teachers go out to study and work in the enterprise. Due to the unclear division of management responsibilities, the student department, academic affairs department and colleges and departments will shirk responsibilities, lacking enthusiasm for the implementation of industry-education integration. Departments as direct providers of courses have a lot of contact with enterprises and bear great responsibilities. Plus the excessively high management cost, teachers and managers have insufficient motivation for industry-education integration. In addition, industry-education integration is mainly implemented in enterprises, and it is difficult for schools to monitor the management process, implementation process, and teaching quality. The process of industry-education integration then receives insufficient attention, so many application-oriented undergraduate colleges find it difficult to maintain

ISSN: 0010-8189 
industry-education integration which becomes a mere formality. In this way, schools pay insufficient attention to industry-education integration, lack strong incentives to the participants in the cooperation, making it difficult for teachers and students to exert subjective initiative, resulting in difficulty in in-depth development of school-enterprise cooperation and industry-education integration.

\subsection{There are insufficient resources for industry-education integration}

For enterprises, some application-oriented colleges and universities have a short period of history, the applied talent training model is not yet mature, and the resource construction is still in the early stage. The teaching team construction, curriculum professional setting, practical teaching management, and internship training platform construction are relatively late. There are not many teachers and students who meet the practical requirements of enterprises, the technical application research and innovation industry technology capabilities are not strong, making it difficult to create direct economic benefits for enterprises. These are all manifestations of insufficient internal strength of the universities themselves. Industry-education integration is a systematic project involving multi-party interests between internal academic subjects and external corporate entities. As an internal subject, universities serve as an invisible link in industry-education integration, making it difficult for external companies to monitor. For invisible links in the internal management of colleges and universities, such as talent training positioning, education and teaching concepts, curriculum and professional construction, and talent training quality, if insufficient attention is paid, industry-education integration will become a mere formality and its sustainable development will be difficult.

3.6 System supply is insufficient. Industry-education integration requires institutional guarantees.

Insufficient system supply is the biggest obstacle to deepening of industry-education integration. Industry-education integration requires effective system design by schools and enterprises, such as school-running orientation, personnel system, training system, salary system, teaching system, scientific research system, internship system, social service system, etc. The traditional system is adverse to industry-education integration. For example, there is a shortage of teachers, the financial system is too strict, the performance salary is not reasonable, the professional setting is not closely linked to the industry, the talent training goal and curriculum setting fail to accurately aim at the social needs, the teaching process and the production process lack integration. Insufficient system supply makes it difficult for schools, enterprises, industry and education parties to develop a clear sense of responsibility, resulting in difficulty in jointly undertaking and completing the talent training mission of cooperative education [11].

\section{Implementation Ways of Industry-Education Integration}

Industry-education integration is a systematic project that involves school education and industry employment. Education and industry should be interconnected and mutually beneficial, the integration should be implemented by promoting school-enterprise ideological consensus, system co-construction, resource sharing, cultural symbiosis, talent co-integration, and mutual benefit. Only by adhering to the organic integration of the education chain and the industrial chain can we continually deepen the industry-education integration and promote the development of dynamic cooperation between schools and enterprises [12].

\subsection{Establish a consensus on ideas and clarify the concept of applied talent training}

Industry-education integration is an economic and educational activity mode of in-depth cooperation between the education and industry circles around the needs of student employment and economic and social development, which takes the cultivation of applied talents as the core. School education and industrial employment must recognize the importance of applied talent training, which is an important conceptual consensus in school-enterprise cooperation. Both parties need strengthen this concept, enhance publicity, and spread the concept of applied talent training to every manager and employee, thus forming a consensus on this concept and orientation. As long as there is "water" irrigation, the "seeds" sown through various measures can germinate to form a green shade. Colleges and universities

ISSN: 0010-8189 
should combine their own conditions, clarify application-oriented positioning, choose appropriate cooperation and integration ways, provide more powerful guarantees for industry-education integration, closely link the industrial chain, innovation chain and strategic emerging industries, and create characteristic specialties, adapt to market demand, expand educational channels to achieve sublimation of industry-education integration. Enterprises have profit-seeking nature and characteristics, which demand high-quality talents and scientific research technology to seek high profits and benefits. Then, enterprises need to find the integration point and acting point of industry-education integration with colleges and universities, participate in the talent training process of colleges and universities, invest human and material resources, establish student internship training bases, provide internship training guidance, participate in technical service research and development, etc. Only in this way can enterprises harvest profits, accelerate the optimization and upgrading of economic structure, improve independent innovation capabilities and core competitiveness. Therefore, industry-education integration is also a major strategy for enterprise development. Consensus of ideas is very important. Only when schools and enterprises reach a consensus on the concept of industry-education integration can the goal of deep industry-education integration be realized [13], because concept serves as thought guidance and action orientation in people's action.

\subsection{Promote the joint construction of systems and improve scientific and effective operating mechanisms}

Industry-education integration is the integration of school and enterprise based on different organizational nature and interest demands. To achieve in-depth industry-education integration, schools and enterprises must focus on cultivating talents that meet the needs of the enterprise and integrate the systems of the two sides, so that there is me in you and you in me, thus cultivating talents in response to market needs. Therefore, schools and enterprises must establish a complete and effective operation system and mechanism. At the level of cooperation and communication, both schools and enterprises should establish coordination and communication mechanism, information feedback mechanism, and technical seminar mechanism to make school-enterprise cooperation more democratic and open with smoother information flow and effective operation. At the practical level, both schools and enterprises should establish a scientific and complete school-enterprise cooperation management system to ensure the integration of mechanisms and promote the industry-education integration. Both schools, enterprises, industry and education parties should promote system reforms to make the industry-education integration system more autonomous and flexible, and practically reform the personnel system, salary system, teaching system, scientific research system, performance evaluation system, and service social system. There is need to implement mutual employment and mutual appointment of personnel in schools and enterprises so that two-way integration can be established in the talent training process to conduct cooperation in educating people and jointly bear the mission of cultivating applied talents.

\subsection{Promote resource sharing and consolidate the material foundation for industry-education integration}

According to the resource dependence theory, the survival and development of any organization need borrow and integrate external resources, and need interact with its surrounding environment by mutual-dependence to achieve its goals. The development of universities and enterprises is no exception. They are connected with each other through industry-education integration, thus influencing and depending on each other in efforts to advance development. Colleges and universities should aim at the needs of industrial development, highlight the characteristics of disciplines, create first-class majors, strengthen connotation construction, and attract high-quality resources and funding from the enterprises and industries. In terms of faculty construction, it is necessary to actively cultivate teachers with "dual vision, dual abilities and dual abilities", attract high-end talents and first-line technical talents from industry enterprises to participate in the training of applied talents, find employment or take a temporary post in colleges and universities. At the same time, we should encourage college teachers to work on temporary posts in industry enterprises. In this way, it is possible to cooperate with enterprises, complement each other's advantages, integrate industry and education; "teach" more excellent talents to better serve the "industry". In terms of construction of student internship training bases, schools and enterprises should cooperate and build together, and the resources of both parties should be shared and used with each other to orient to each other's development direction and form a school-enterprise community of interests. The built base and investment should help develop industry

ISSN: 0010-8189 
enterprises and improve school education service level, achieve integration of school and enterprise resources to complement each other. By integrating various complementary resources of schools and enterprises, we should create a resource chain and "environmental field" between school education and industry enterprises, thus forming a joint training talent mechanism of school-enterprise resource sharing, talent sharing, process co-management, and mutual benefit [14].

4.4 Promote cultural symbiosis and lay a foundation for the cultivation of outstanding talents

Cultural symbiosis refers to a cultural state of mutual connection, close interdependence, and coexistence between two or more cultures. It provides a space for the survival and development of multiple cultures. Its driving force originates from the combined force of the internal driving force and external pressure of cultural development. The current implementation of industry-education integration and school-enterprise cooperation is to integrate the two cultures of school and enterprise to form a collective culture at the level of community of school-enterprise interests [15]. This is a new strategy for the deep development of industry-education integration, and the fundamental value orientation of cultural symbiosis. To a certain extent, school culture demonstrates the unique concept and characteristics of school development, which is the core and soul of the school. School culture derives from the inheritance of history, the accumulation of experience, and the refinement of practice. It is the sum of value, behavior, moral and life concept formed in the long-term education, teaching and life and commonly recognized by the school teachers, students and employees. Corporate culture refers to the sum of corporate ideology, i.e. a series of spiritual achievement and cultural concept formed in long-term enterprise production and operation, including corporate spirit, corporate ethics, corporate values, etc. [14]. Through industry-education integration and school-enterprise cooperation, schools and enterprises absorb each other's cultural ideas, seek symbiotic education and symbiotic development, strengthen moral education and cultivate people under the leadership of culture. In theoretical study and practical training, students are influenced not only by the school campus culture, but also by the corporate culture, so that students have the spirit of humanistic care as well as the spirit of enterprise and sense of responsibility, thus able to quickly familiarize with workplace situation and get prepared for employment. By integrating the cultural concepts of both schools and enterprises, it is possible to lay the foundation for the cultivation of high-quality talents in the new era.

\subsection{Promote the integration of talents and strengthen the construction of talent team}

Talent acts as the most active and positive factor in industry-education integration. Without the integration of talents, industry-education integration will become a mere formality. At present, most of the application-oriented universities are a result of transformation of traditional universities. The school-running time is relatively short, and the teachers lack applied technology and innovative research capabilities. However, engineers and industry experts who have practical skills and applied technology capabilities in enterprises master more tacit knowledge and possess strong sensitivity to new technologies and new formats. To cultivate modern applied talents, colleges and universities must integrate the concept of industry-education integration into the whole process of talent training, cultivate a group of "double qualified" teachers according to respective professional settings. Then, teachers from "school to school" need take temporary post in enterprises to improve their practical application capabilities. Schools can also set up "Entrepreneur Class", implement the industry mentor program, combine both full-time and part-time modes, attract industry experts into the school, introduce corporate experts into the classroom to help train "double qualified" teachers, provide student internship training, employment and entrepreneurship, make arrangement for enterprise employee training. In this way, school teachers and corporate personnel infiltrate each other, grow together, thus continuously improving the professionalism of teachers, students and employees.

\subsection{Promote win-win benefits and strengthen the motivation for industry-education integration}

Industry-education integration and school-enterprise cooperation, characterized by mutual benefit, take satisfaction of interest appeals as the purpose. Interests are the bond of industry-education integration. [15] School-enterprise cooperation can last long and deepen only when each other's needs are met. Win-win benefit stimulates both schools

ISSN: 0010-8189 
and enterprises to devote more energy into in-depth integration and cooperation to achieve greater success, thus forming a virtuous circle. On the contrary, if the expected results are not achieved in the cooperation, and there is no profit, both the school and the enterprise will react negatively, avoid it and refuse to cooperate. Therefore, mutual benefit is the foundation of industry-education integration. In industry-education integration and school-enterprise cooperation, the school pursues the cultivation of applied talents to meet the needs of the market. This requires that school's professional setting should link with industry enterprises to grasp the development trend of the industry, carry out education and teaching reforms, and cultivate the talents needed by enterprises. The pursuit of enterprises is to obtain greater economic benefits, which demands qualified talents as a guarantee. This requires enterprises to select innovative talents from schools to join the enterprise in new product research and development, technological innovation, etc., thus saving costs and improving the overall corporate efficiency. For this reason, it is necessary to establish a community of interests between schools and enterprises to share responsibilities and enjoy rights, thus truly deepening industry-education integration.

\section{Conclusion}

Industry-education integration and school-enterprise cooperation are the breakthrough point for the transformation and development of universities, an effective way to serve the development of the local economy, an inevitable choice for the training of applied talents and innovative talents, and an important institutional arrangement for the transformation and upgrading of industry enterprises and provision of talents. In the context of the popularization of higher education and a new normality in the economy and society, new requirements and challenges are raised in the professional setting, personnel training, scientific research, and social services of application-oriented universities. Universities should base themselves on the production practices and talent needs of enterprises, take the initiative to connect with the industry, insist on setting up professional chains based on industrial chains, strengthen teaching model reforms around connotation construction, and constantly innovate talent training patterns, thus better providing targeted, innovative, and practical talents for industry enterprises. Enterprises also should absorb the values, spiritual pursuits and scientific research results of higher education institutions, conduct collaborative innovation, share industry-university resources, solve scientific and technological problems, thereby boosting industrial development. In view of the economic and social needs for talent cultivation, "industry-education integration and school-enterprise cooperation" are particularly important. This requires colleges and universities and industry enterprises to form an education community in personnel training, a governance community in organization, an innovation community in technical skills, and a community of interests in target orientation. Only through integrated development of the school and enterprise can we achieve sound development of industry-education integration.

\section{Acknowledgements}

Supported by Projects of Hunan Province Key Project of Educational Science Planning "Research on the Cooperative Education Mechanism via Industry-Education Integration in Application-oriented Undergraduate Colleges" (Project Approval Number: XJK20AGD007); Hunan Provincial Teaching Reform Research Project in Ordinary Colleges "Exploration and Practice of Applied Talent Cultivation Based on Industry-Education Integration" (Xiang Jiao Tong [2018] No. 436-903); The Double First-Class Discipline Construction Project of Undergraduate Colleges in Hunan Province- Applied Characteristic Discipline of Sociology (Xiang Jiao Tong [2018] No. 496).

\section{References}

[1] Y.Q. Duan. "Research on the Path of Cultivating Innovative Talents in Undergraduate Colleges under the Background of Industry-Education Integration," Fortune Time, vol. 1, pp. 168-171, 2019.

[2] X.J. Zhang, L. Yan. "Building a new ecology of industry-education integration to promote high-quality development-Taking Shaanxi Province as an example," China Economic \& Trade Herald, vol. 12, pp. 72-74, 2019.

[3] National pilot implementation plan for industry-education integration, "People's Daily", October 11,

ISSN: 0010-8189 
2019.

[4] X.P. Jiang, H. Sheng. "Mdong Technology: industry-education integration, serving the digital economy. Tsinghua Business Review,” vol. 11, pp. 123-129, 2020.

[5] X.H. Sun. "Research on the path of cultivating applied talents through industry-education integration in local engineering colleges," Harbin University of Science and Technology, 2017.

[6] N.Y. Chen, C.Q. Zhou, Z.P. Wu. "The connotation and implementation way of industry-education integration ," Chinese University Technology Transfer, vol. 8, pp. 40-42, 2014.

[7] H. Xing, Y.Z. Li. "Investigation and analysis of the current situation of industry-education integration in private colleges and universities," Education and Vocation, vol. 12, pp. 24-27, 2015.

[8] O.Y. He, Dai Chuntao. "A preliminary study on the connotation, classification and characteristics of enterprises integrating production and education," Chinese Vocational and Technical Education. vol. 24, pp. 51-56, 2019.

[9] R.Z. Luo. "Institutional logic analysis of the policy of industry-education integration in vocational education," Vocational and Technical Education, vol. 6, pp. 8-13, 2016.

[10] L.J. Dou. "Research and practice of diversified industry-education integration talent training model based on the "win-win mechanism". Journal of Changchun Institute of Technology (Social Science Edition), vol. 3, pp. 62-65, 2018.

[11] J. Zhang. "The theory, connotation and implementation of deep industry-education integration. Journal of Henan Institute of Science and Technology," vol. 8, pp. 1-4, 2017.

[12] Y.S. Li, Z.H. Niu. "On the integration of production and education and its deepening content," Beijing Education (Higher Education), vol. 5, pp. 19-22, 2018.

[13] J. Zhang. "The theory, connotation and implementation of deep industry-education integration. Journal of Henan Institute of Science and Technology, vol 8, pp. 1-4, 2017.

[14] Y.S. Li, Z.H. Niu. "On the integration of production and education and its deepening content," Beijing Education (Higher Education), vol. 5, pp. 19-22, 2018.

[15] L. Zhang, J.F. Li. "On the endogenous driving force that promotes industry-education integration," China Adult Education, vol. 24, pp. 43-46, 2017. 